\title{
13
}

\section{Identity, Discernibility, and Composition}

\author{
Donald L. M. Baxter
}

To think of a whole as something in addition to its parts opposes common sense. It is a stretch to think that when holding a six-pack you are holding something distinct and in addition to the six cans and the plastic yoke that connects themsomething that occupies exactly the same space that they collectively occupy and that is exactly like how they collectively are save that it is one and they are many. A natural reaction is to say that the whole just is the parts, but there is an artifice in saying it that way. ${ }^{1}$ We normally tend only to say such things in jokes, such as when we say that a helicopter is 50,000 parts flying in close formation, or in idioms, such as when we say, of a man and a woman in love, that they are a unit. We don't ordinarily make many-one identity claims so baldly, but switch to the language of part and whole. That switch is not a switch away from the language of identity, I contend, it is just a complication of the language of identity. Otherwise the opposition to common sense remains, whereas it should be avoided. The best metaphysics can do, if it is to be believable, is to find ways to make sense of our common sense commitments. When we break free of those commitments for the sake of theoretical virtues, we may admire the purity and elegance of the result, but we have lost contact with the reality that pressed our common sense beliefs on us.

Granted, common sense contains apparent confusions, gaps, and contradictions, like a rough draft of a philosophy paper. That does not entail that the underlying view really has these problems. A metaphysician can try to revise the draft in order to sort out the surface infelicities in a way true to what common sense formulations are getting at. The project is descriptive metaphysics that

\footnotetext{
1 e.g. "It just is them. They just are it" (Lewis 1991, 81).
} 
improves on the presentation of the theory underlying common sense without trying to change it. My suspicion is that, when suitably presented, the theory underlying common sense will be better than its less descriptive, more deeply revisionary rivals. ${ }^{2}$ After all, it has been tested for longer.

The present goal is to find a workable way to say that the whole is the parts, and literally mean an identity between them. The way of talking will be stilted, but it will capture a truth expressed in more common ways of talking of wholes and parts. A natural way to proceed is to say that whole and parts are the "same thing" counted in different ways-as one and as six, for instance. Of course, the grammatical singularity of "same thing" is not supposed to privilege one count over the other. A grammatically singular term can refer to several things collectively.

A seemingly easy way for this approach to work is to say that one count is strict and philosophical and the other count is loose and popular. In other words, one count is true and the other count is false but useful. However, this way is only easy on the assumption that the strict count is the finer grained one and the loose count is the coarser grained one. On that assumption it is the six cans that exist and talk of the six-pack is just talk of them collectively as if they were a unitary thing. Philosophers have long recognized and described our ability to do this. ${ }^{3}$

An alternative way is to think that the coarse-grained count is the strict count, and the fine-grained count is loose-that the whole is strictly one and only loosely many. That would require a way to discern some sort of complexity in a single thing which can be treated as a numerical complexity-a composition by distinct things-even if it isn't really. Such a notion of diversity in the loose and popular sense is not familiar.

Both alternatives fall short, however. It opposes common sense to say that the six-pack or the helicopter is really one thing and not many, or really many and not one. Common sense wants it both ways. The descriptive metaphysician should respond by saying that the whole and the parts collectively are somehow the "same thing" counted differently, where both counts are strict and philosophical. Trying to make this response work gives rise to the view that David Lewis dubbed "Composition as Identity."

There is more than one way to say that composition is identity. Yi has distinguished the Weak Composition thesis from the Strong Composition thesis, and attributed the former to David Lewis while noting that Lewis associates

\footnotetext{
2 Cf. Strawson $(1959,9)$.

3 See Arnauld and Nicole (1996, 111-13), and both the Butler and Reid selections in Perry (1975, 101, 112). I have often repented of jettisoning (against the wise advice of Michael Frede) the connotation of being false from my early usage of "loose" when talking of loose counts and strict counts. I wish I had coined new expressions, such as "coarse-grained" counts and "fine-grained" counts. "Loose identity" should retain its original connotation of being falsely supposed identity. See Baxter (1988); cf. Baxter (2001).
} 
something like the latter with me. ${ }^{4}$ Weak Composition is the thesis that the relation between the parts collectively and their whole is closely analogous to numerical identity. Strong Composition is the thesis that the relation between the parts collectively and their whole is numerical identity. Yi is right that Strong Composition does not fully reflect my view. We must recognize further what, borrowing Lewis's characterization, could be called the "stronger, and stranger" Composition thesis, or what I'll call the Stranger Composition thesis for short. ${ }^{5}$ On Strong Composition, it is only collectively that the parts are identical with the whole. On Stranger Composition, they are individually identical with it as well, where the identity is more fundamental than numerical identity. ${ }^{6}$ I will explain and further motivate this thesis.

My theory has it that the whole is the distinct parts counted as identical. On a fine-grained standard of counting the parts are distinct from each other; on a coarse-grained standard they are identical with each other. The standards are equally good, though may not be equally salient. So the whole is the parts on the coarse-grained standard of counting on which they are identical. For example, take a six-pack. On one standard of counting, what is consumed as a unit is a unit. On another standard, what is priced as a unit is a unit. On the first standard the six-pack is six things, and on the second standard it is one thing. ${ }^{7}$ Successively pointing to distinct cans on the first standard is pointing to the same thing on the second: the same whole.

This theory sounds like a theory of relative identity, and in some respects it is. ${ }^{8}$ But note that the identity across standards is absolute. The very thing itself is (or the very things themselves are) counted variously. I think there is tacit recognition of the absolute identity in Lewis's claim that "the many and the one are the same portion of Reality" and Frege's claim, "While looking at the same external phenomenon, I can say with equal truth both 'It is a copse' and 'It is five trees"' (my emphases). ${ }^{9}$ Something on one standard and some things on another are simply identical. It would be odd to call it numerical identity, given that the relation can

4 Yi (1991, 149 and 158 n. 13). Lewis (1991, 84 n. 12). See also Sider (2007).

5 Lewis (1991, 84 n. 12).

6 In a sense, Strong Composition is a consequence of my view. On the standard of counting on which the whole is a single individual, its parts are aspects numerically identical to it, both collectively and individually.

7 Other, more philosophical standards of counting things might be: Count what are inseparable as a unit; count what are at the same place at the same time as a unit; count what is indivisible as a unit; count what are organically related as a unit; count what thinks as a unit; count everything collectively as a unit; etc.

8 Geach (1967).

9 Lewis $(1991,87)$. Frege $(1959, \$ 46,59)$. Austen renders derselben äussern Erscheinung as “one and the same," but that can't be right. Frege uses "external phenomenon" as a way to be neutral about how many things there are. Cf. Lowe $(2003,323)$. I'm grateful to Jonny Cottrell for discussion. 
be many-one. Further, number is relative to standard of counting, so numerical identity is relative to standard of counting as well. So I call the identity "crosscount" identity. But note that cross-count identity is not some exotic variant of or analogue to identity; it is identity-something being itself. A part of the philosophical tradition has fixated on numerical identity as what underlies variation in quality, and neglected to see how identity itself can underlie variation in number.

There are other parts of the philosophical tradition, however, going way back. For instance, the young Socrates declares:

So if - in the case of stones and sticks and such things-someone tries to show that the same thing is many and one, we'll say that he is demonstrating something to be many and one ... and we'll say that he is saying nothing astonishing, but just what all of us would agree to. ${ }^{10}$

Likewise Berkeley declares:

the same thing bears a different denomination of number, as the mind views it with different respects. Thus, the same extension is one or three or thirty-six, according as the mind considers it with reference to a yard, a foot, or an inch. ${ }^{11}$

Lewis and Frege echo Socrates' and Berkeley's use of "same” here. Again, if the same thing can be different numbers of things, that sameness is identity but not numerical identity.

Despite the usage of these authorities, some might protest that they know what identity is if they know what anything is, and it is numerical identity. Identity is a shining exception to the general murkiness of philosophical subject matters. The conjunction of the Identity of Indiscernibles and the Indiscernibility of Identicals (Leibniz's Law) captures it exactly. Some things are the same if and only if all the same things are true of them.

I can see how those focused on mathematics would come to this view of identity. For eternal, simple objects this view is fine. But to carry it over to the world of altering and composite things is to try to impose the still purity of the mathematical realm on our world's buzz and bloom.

The problem is the indiscernibility of identicals_-if something and something are numerically identical then all the same things are true of them. We hold this principle so firmly because we do not distinguish it from the supremely valuable principle that contradictions are not true of anything. ${ }^{12}$ Whether we can hang on to non-contradiction in all cases has been disputed, but its loss in any case would be a grievously high price exacted on our concept of reality.

10 Plato, Parmenides 129d, my emphasis on "same."

11 Berkeley (1982, part I, \$12), my emphasis on “same." 12 See Baxter (1989). 
Countenancing the discernibility of identicals, however, ought not to be regarded as accepting contradiction. Consider alteration. On the face of it, the same thing becomes different. This thing as it now is differs from itself as it was. That something differs from itself in such a case itself is as plain as day. So there is some way for something to differ from itself without contradiction. An account that does not preserve this literal differing makes alteration an illusion. Commitment to the indiscernibility of identicals precludes the literal differing. It endarkens what is plain as day.

The principle prevents us, furthermore, from recognizing the plain fact that something can alter with respect to the number of things it is-one thing can become two things. An amoeba divides; it is now two amoebas. It itself is now two.

Willingness to rethink the indiscernibility of identicals begins to open one to the thought that the Stranger Composition thesis concerns identity itself. Identicals may differ, even in the number of things they are. Differing cans may be identical with each other on a coarse-grained standard of counting where a sixpack counts as a unit, though they be distinct from each other on a finer grained standard where the cans count as units. Or, adding the complications of time, a single amoeba which becomes a scattered object, on one standard of counting, may be distinct things which separate into amoebas, on another. ${ }^{13}$

To understand the thinking behind the Stranger Composition thesis with its discernibility of identicals, start with the commonplace that we can confuse things. We can regard really distinct things as identical. We can also pretend to confuse things. Exploring a way to engage in this pretense will help with finding a way to think about identicals as discernible. For instance we can take this pen and this page to be identical. If someone asks how many there are, we say "One" instead of "Two." When asked to count them we point to the pen and say "One" and point to the page and say "Same again," instead of saying "One" then "Two." When asked to touch the thing we are pretending them to be, we touch either or both. When asked if we see it we say "Yes" if we see either or both. Suppose the pen is blue and the page is white. If someone asks the color of the pretended thing we say "Partly blue and partly white." If someone asks if it has a blue part and a white part, we say "No," if we are staying strictly within the pretense, for we are taking the pen and the page to be identical. If someone asks whether the pretended object resembles the sky we say, "Yes and no. Insofar as it is blue it resembles the sky, but insofar as it is white it does not." Or we might say, "In one respect it

${ }^{13}$ Perhaps the two standards share the form "Count as a unit what is an amoeba at $\mathrm{t}$ " and differ only in that one refers to the earlier time and the other to the later time. At the different times, the different standards are salient. 
resembles the sky but in another respect it does not." This response may feel for a second like a contradiction, but there would be contradiction only if we said, "In one respect it resembles the sky but in no respect does it resemble the sky."

Someone still sensing the contradiction may argue that outside the pretense the pen in some respect is blue and the paper in every respect is not blue. Therefore, pretending that they are identical is pretending that there is something that in some respect is blue and yet that in every respect is not. However, this objection involves a scope confusion. What we are pretending is that there is something such that in the respect in which it is just like the pen, it is blue, and in the respect in which it is just like the page, it in every respect is not blue. Nesting the respect-phrases limits the respects quantified over to those of the supposed object just insofar as it is like the page. The objection, by overlooking the nesting, treats the quantification as not thus limited. The upshot is that there is a way to pretend that pen and page are identical with each other that includes their qualitative differences without pretending a contradiction is true. ${ }^{14}$

In other words, we can pretend that things are identical without pretending that they are indiscernible. We pretend that they are qualitatively differing but numerically identical aspects of something. Doing so does require that we posit a non-numerical kind of distinction that supports differing. Call it an aspectival distinction. Thinking through the pretense gives us this way to conceive of the discernibility of identicals.

You have experienced self-differing-the aspectival distinction-if you have experienced conflicting desires. To keep it impersonal, consider this case:

[1] Shirley insofar as she loves Ralph, wants to help him.

[2] Shirley insofar as she hates Ralph, has no desire to help him.

Sentences [1] and [2] can both be true at once. In that case we must avoid the conclusion

[3] Shirley wants to help him and has no desire to help him

unless it is elliptical for

[4] One aspect of Shirley wants to help him and another has no desire to help him.

Here are differing aspects of Shirley.

\footnotetext{
14 I'm grateful for discussion with Philipp Blum. For considerations supporting my use of expressions like "the pretended object insofar as it is blue" as referring expressions, see Landman (1989).
} 
My conclusion could be resisted by saying that [3] does not need an implicit appeal to aspects in order to avoid being a contradiction. [3] could more perspicuously be put

[5] Shirley wants to help and wants not to help him.

That is, she has a desire to help and a desire to withhold help. The desires conflict-one cannot fully act on both-but there is no even apparent contradiction in having conflicting desires.

It seems to me, however, that desires are not like quarrelsome children in being opponents one is merely related to. To have conflicting desires is like trying to move in opposite directions. It is "to take something to oneself and to cast it off" as Plato puts it. This internal opposition indicates complexity, as argued in the Republic. ${ }^{15}$ It is why we say in such situations that we are torn. Plato's view has been justly influential in pointing out this complexity which is downplayed by the objection. However, it seems to me to be going too far to conclude with Plato that internal opposition indicates quantitative complexity-that the soul has numerically distinct parts. It doesn't. Nonetheless, one differs from oneself in trying to move in one direction while trying to move in the other. Thus even if [3] merely indicates conflicting desires, it still brings into consideration different aspects.

Furthermore, it seems to me that Shirley's conflict is poorly characterized as conflicting desires. She might better characterize her state with

[6] Part of me wants to help him and part of me has absolutely no desire to help him

except for the fact that she does not literally have these parts. Shirley is not merely having two desires with conflicting content. She is partly wanting to help while partly rejecting helping. So, [3] is more perspicuous than the proposed reformulation [5], and [4] is the most perspicuous. One who has experienced such conflict has experienced differing aspects in oneself.

There is a need to recognize an aspectival distinction even on the familiar view of parts and wholes. Suppose the pen and page are parts of a whole. Suppose we accept the familiar view that each individually, as well as the two collectively, is distinct from the whole. What color is the whole? True, it has a part that is blue and a part that is not blue, but that is changing the subject. What about the whole itself? Obviously it has color. Suppose that color is intrinsic. ${ }^{16}$ Then the whole either lacks color, since at best it would have color only in relation to its parts, or

15 Plato, Republic 435c-441c, esp. 437b.

16 Or suppose that the whole is partly bent and partly straight. Cf. Lewis (1986, 202-4, 210). 
it is partly blue and partly not blue, in the way I have explained by appeal to the aspectival distinction. It does not lack color, so it has aspects.

One might resist aspects by saying merely that the whole has a distributional property of being blue here and not blue there. ${ }^{17}$ While this is true, it does not by itself explain the "Yes and no" answer to the question whether the whole resembles the blue sky. Insofar as it is blue it resembles the sky; insofar as it is white it does not. Something with a non-uniform distributional property differs from itself. It has aspects.

With the pretense of the identity of pen and page explained by appeal to aspects, now note how we can switch back and forth between the pretense and reality. Even if the number of things we take there to be varies with the switches, there is an absolute identity of the subject matter-the pen and the page-between reality and pretense.

The next step is to wonder-given the workability of the pretense-how we know what is fact and what is pretense about the number of things. How do we know that the pen and page are really two things? How do we know that there is not really one object, with differing aspects, that we commonly but mistakenly count as two things? For that matter, how do we know that there are not competing but equally real standards for counting such that pen and page are really one thing on one standard and really two things on another standard? On this third alternative the counts would distinguish aspects of the pen and page that differ with respect to number. That would mean that pen and page on one standard of counting would be aspectivally distinct from pen and page on the other. That is, the pen and page insofar as they are one single thing would be an aspect of them and the pen and page insofar as they are two distinct things would be a differing aspect of them. Call these aspects differing with respect to number "count-aspects."

There is no observable evidence to discriminate between these three alternatives, but our pre-theoretical commitments point to the third.

We ordinarily are committed to a whole being a single thing and the parts being several things. Further, we take being many to be the opposite of being one. If there is one, there are fewer than many. If there are many, there are more than one. Despite this difference, we are surprised to think of the whole as a distinct thing in addition to the parts. We are ordinarily somehow committed to the whole just being the parts. How can a theory be elaborated that preserves all these pre-theoretical commitments: that the parts are many, the whole is one, being many is the opposite of being one, and the parts are identical with the whole? 
Weak Composition will not do because on it the parts are not identical with the whole. There is only an analogue of numerical identity that is not any sort of identity.

Strong Composition will not do either. Assuming the parts are numerically distinct, and the whole is numerically identical with the parts collectively, it follows that the whole is not truly one thing. Alternatively, if the whole is a single thing and the whole is numerically identical with the parts collectively, then the parts are not truly many things.

We might try to support Strong Composition by saying, with Frege, that the whole is one thing relative to a concept, such as the concept six-pack, and six things relative to the concept can. ${ }^{18}$ But making number relative to concept is too much like an appeal to number in a loose and popular sense-the number something is merely conceived to be instead of the number it is in itself. ${ }^{19}$

Let me explain. Take Frege's claim quoted earlier: "While looking at the same external phenomenon, I can say with equal truth both 'It is a copse' and 'It is five trees'." He is saying that exactly one thing falls under the concept copse, and exactly five things fall under the concept tree, and something falls under the concept external phenomenon that is identical with it (the copse) and with them (the trees). The concept external phenomenon does not determine how many things fall under it. So how many things the external phenomenon is depends on which of the other concepts it falls under. So how many things the external phenomenon is, is relative to a way of conceiving of things. But that can't be right. How many things something is depends on what is identical and distinct from what, and that is independent of ways of conceiving things. What is identical and distinct from what is a matter of how things are in themselves. ${ }^{20}$

Alternatively, Strong Composition could hold that there is really no opposition between being one and being many, in a way Sider has explored, though not endorsed. A whole with parts just is both one and many. But this is another pretheoretical commitment lost.

Only Stranger Composition will do. In the case of whole and parts, there are things such that they are many distinct things on some standard of counting and are one and the same thing on another. The standards are both real, so our sixpack is really six things and really one thing, and the six on one standard are really identical with the one on the other. The differing count-aspects are identical with the six-pack itself, so the numbers are not simply applied relative to concepts. Further, the number of things something is (relative to a standard for counting),

18 See Wallace (2011a, 2011b).

19 The analogy here is with identity in the loose and popular sense, which is a relation between things falsely but usefully attributed identity.

20 Cf. Alston and Bennett $(1984,558)$. I'm grateful to Marcus Rossberg for discussion. 
is a matter of it itself having aspects that differ in number. Finally, being one is the opposite of being many, which is why nothing can be both on the same standard of counting.

In sum, the parts are, both individually and collectively, cross-count identical with the whole. What are distinct things in one count are differing but numerically identical aspects of a thing in the other. Composition is cross-count identity.

\section{References}

Alston, William P. and Bennett, Jonathan (1984) "Identity and Cardinality: Geach and Frege," Philosophical Review, 93: 558.

Arnauld, Antoine and Nicole, Pierre (1996) Logic or the Art of Thinking, Cambridge: Cambridge University Press.

Baxter, Donald L. M. (1988) "Identity in the Loose and Popular Sense," Mind, 97: 575-82.

Baxter, Donald L. M. (1989) "Identity through Time and the Discernibility of Identicals," Analysis, 49: 125-31.

Baxter, Donald L. M. (2001) "Loose Identity and Becoming Something Else," Noûs, 35: 592-601.

Berkeley, George (1982) A Treatise Concerning the Principles of Human Knowledge, ed. Kenneth Winkler, Indianapolis, IN: Hackett Publishing.

Frege, Gottlob (1959) The Foundations of Arithmetic: A Logico-Mathematical Enquiry into the Concept of Number, tr. J. L. Austin, Oxford: Basil Blackwell.

Geach, P. T. (1967) "Identity," Review of Metaphysics, 21/1: 3-12.

Landman, Fred (1989) “Groups, II," Linguistics and Philosophy, 12: 723-44.

Lewis, David (1991) Parts of Classes, Oxford: Basil Blackwell.

Lewis, David (1986) On the Plurality of Worlds, Oxford: Basil Blackwell.

Lowe, E. J. (2003) "Identity, Individuality, and Unity," Philosophy, 78: 323.

Parsons, Josh (2004) "Distributional Properties," in Frank Jackson and Graham Priest (eds), Lewisian Themes: The Philosophy of David K. Lewis, Oxford: Oxford University Press, 173-80.

Perry, John, ed. (1975) Personal Identity, Berkeley and Los Angeles: University of California Press.

Plato (1974) Republic, tr. G. M. A. Grube, Indianapolis, IN: Hackett Publishing.

Plato (1996) Parmenides, tr. Mary Louise Gill and Paul Ryan, Indianapolis, IN: Hackett Publishing.

Sider, Theodore (2007) "Parthood," Philosophical Review, 116: 51-91.

Strawson, P. F. (1959) Individuals, London: Routledge.

Wallace, Megan (2011a) "Composition as Identity: Part 1," Philosophy Compass, 6/11: 804-16.

Wallace, Megan (2011b) “Composition as Identity: Part 2," Philosophy Compass, 6/11: $817-27$.

Williamson, Timothy (1988) "Equivocation and Existence," Proceedings of the Aristotelian Society, 88: 109-27.

Yi, Byeong-uk (1999) “Is Mereology Ontologically Innocent?” Philosophical Studies, 93: $141-60$. 
